\title{
Can policy forums overcome echo chamber effects by enabling policy learning? Evidence from the Irish climate change policy network - CORRIGENDUM
}

Paul M. Wagner and Tuomas Ylä-Anttila

https://doi.org/10.1017/S0143814X18000314 published by Cambridge University Press 22 October 2018

Within the original publication a figure contained incorrect data and a figure was mislabelled. The correct representation of the figures are shown here.

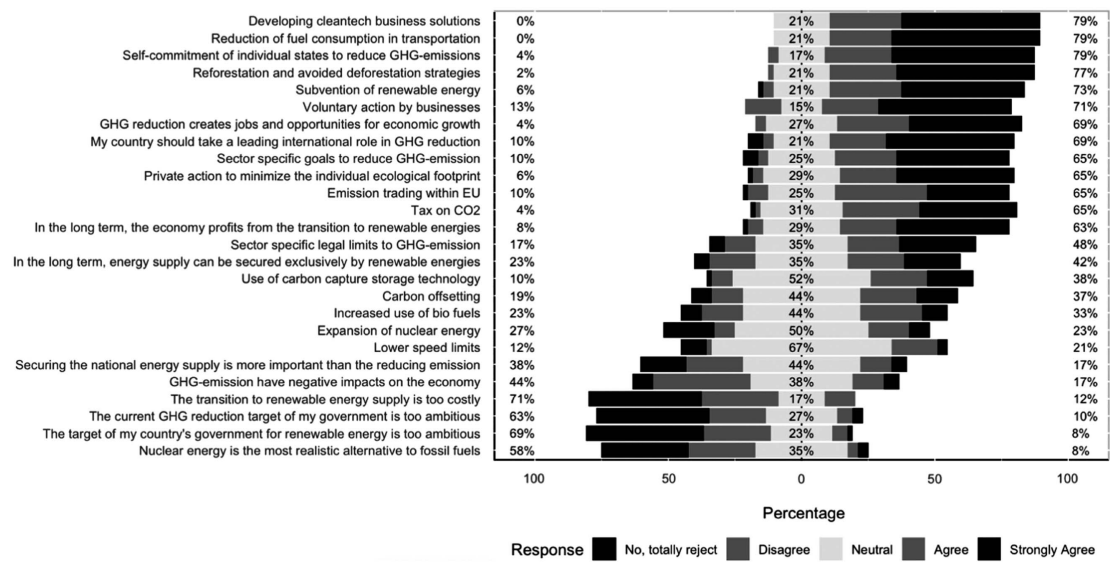

Figure 1. Respondents' opinions of 26 policy ideas. GHG = greenhouse gas. 


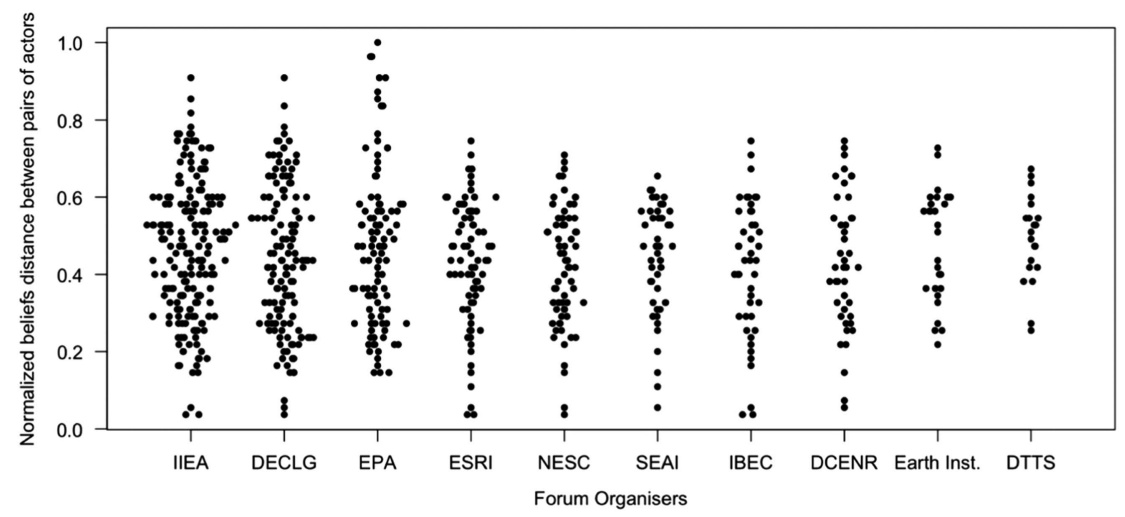

Figure 2. Normalized distance between the beliefs of each pair of actors that participated in the ten most attended forums.

The authors apologise for the error.

\section{Reference}

Wagner PM and Ylä-Anttila T (2018) Can policy forums overcome echo chamber effects by enabling policy learning? Evidence from the Irish climate change policy network. Journal of Public Policy, first published online 22 October 2018. doi: 10.1017/S0143814X18000314.

Cite this article: Wagner, P.M., Ylä-Anttila, T. 2020. Can policy forums overcome echo chamber effects by enabling policy learning? Evidence from the Irish climate change policy network - CORRIGENDUM. Journal of Public Policy 40:212-213, doi:10.1017/S0143814X18000429 